\title{
QUALIDADE FÍSICA DE UM CAMBISSOLO HÁPLICO SOB DIFERENTES USOS NA BACIA DO CÓRREGO DOS MICOS, PARATY (RJ)
}

\author{
PHYSICAL QUALITY OF A HAPLIC CAMBISOL UNDER DIFFERENT \\ USES IN THE CÓRREGO DOS MICOS RIVER BASIN, PARATY (RJ) \\ CALIDAD FÍSICA EN UN CAMBIOSOL HÁPLICO BAJO DIFERENTES \\ USOS EN LA CUENCA DEL ARROYO MICOS, PARATY (RJ)
}

Luana de Almeida Rangel - Universidade Federal do Rio de Janeiro

- Rio de Janeiro - Rio de Janeiro - Brasil

luarangel24@gmail.com

Antonio Jose Teixeira Guerra - Universidade Federal do Rio de Janeiro
- Rio de Janeiro - Rio de Janeiro - Brasil
antonioguerra@gmail.com

\section{Resumo}

Esse artigo aborda a bacia do córrego dos Micos, no município de Paraty, que está localizada em uma Área de Proteção Ambiental, com o objetivo de analisar o papel de algumas propriedades do solo, em conjunto com o uso e manejo do solo, para compreender como eles podem alterar um Cambissolo Háplico. Para atingir esses objetivos, amostras de solo foram coletadas a diferentes profundidades $(0-10$ e $10-20 \mathrm{~cm})$, para serem analisadas em laboratório; e um pluviógrafo foi instalado para coletar dados pluviométricos. As propriedades do solo incluem a textura, densidade aparente e estabilidade dos agregados. 0 s resultados demonstram 0 papel que essas propriedades têm para compreender os indicadores de qualidade dos solos. Comparando os diversos usos da terra, foi possível destacar que tem ocorrido degradação da estrutura do solo na área de plantação de aipim, que sofre com queimadas constantes. Os resultados também apontam para a necessidade de levantamentos de campo, em conjunto com análises de laboratório, para mostrar como esses estudos podem ser úteis para mostrar aos moradores locais como eles podem melhorar o uso e o manejo para evitar a degradação dos solos.

Palavras-chave: Estabilidade de agregados, queimadas, degradação, erosão hídrica.

\section{Abstract}

This paper regards the córrego dos Micos river basin, in Paraty Municipality, which is located within an Environmental Protection Area, in order to assess the role of some soil properties, together with land use and management, to understand how they might affect Haplic Cambisol. In order to achieve this target, soil samples have been collected, at different depths $(0-10$ and $10-20 \mathrm{~cm})$ and have been analyzed in the laboratory, to assess physical and chemical properties. In addition, a pluviograph was installed to collect rainfall data. These include soil texture, bulk density and water aggregate stability. The results point out to the role that these soil properties have in understanding the indicators of soil quality. Comparing different land uses, it has been possible to outline that there has been a degradation of the soil structure on the manioc plantation area. The results also point out toward the need of field surveys, together with laboratory analysis, in order to show how these studies can be useful to show the local residents how they can improve the land use and management, in order to avoid land degradation.

Keywords: Aggregate stability, fires, degradation, water erosion.

\section{Resumen}

En este artículo se discute la cuenca del arroyo de los Micos, en el municipio de Paraty, localizado en un área de Protección Ambiental, con el fin de analizar el papel de algunas propiedades de suelo, en conjunto con el uso 
y manejo del suelo, para entender cómo pueden cambiar un Cambisol Háplico. Para lograr estos objetivos, se recogieron muestras de suelo de diferentes profundidades $(0-10$ y $10-20 \mathrm{~cm})$, para ser analizadas en laboratorio. Además de eso, se instaló un pluviómetro para recoger datos de precipitación. Las propiedades del suelo incluyen textura, densidad aparente y estabilidad de los agregados en agua. Los resultados demuestran el papel que estas propiedades tienen en la acción de entender los indicadores de calidad del suelo. Comparando los diferentes usos de la tierra, fue posible señalar que se ha producido la degradación de la estructura del suelo en el área de siembra de yuca que sufre con constantes incendios. Los resultados también indican la necesidad de estudios de campo en conjunto con el análisis de laboratorio para mostrar cómo estos estudios pueden ser útiles para mostrar a los habitantes de la localidad cómo pueden mejorar el uso y la gestión para impedir la degradación del suelo.

Palabras clave: estabilidad de agregados, quemadas, degradación, erosión hídrica.

\section{Introdução}

Considerando o solo como um sistema aberto (Guerra; Mendonça, 2004; Morgan, 2005), os diferentes usos e práticas de manejo adotados interferem diretamente nos atributos físicos e químicos do mesmo. A complexidade dos processos físicos e químicos que ocorrem no solo, muitas vezes, é de difícil mensuração (Kelting et al., 1999), principalmente quando ocorre alguma perturbação no sistema.

A estrutura é o principal atributo do solo que sofre quando ocorre algum tipo de degradação (Silva; Castro, 2014). A diminuição da qualidade da estrutura do solo pode ocorrer tanto em subsuperfície, com o surgimento de camadas compactadas, quanto em superfície, com o aparecimento de finas crostas, resultando em menores taxas de infiltração de água, maior compactação e maiores taxas de escoamento superficial, o que irá acelerar mais ainda o processo de degradação, e, portanto, a erosão (Portela et al., 2010).

Por consequência, a estrutura é um dos atributos mais importantes para a adaptação das espécies e pode ser avaliada pela densidade do solo, porosidade, estabilidade de agregados, resistência do solo, permeabilidade, entre outros (Schneider et al., 2007; Pedrotti; Mello Júnior, 2009). Estes atributos podem ser utilizados como indicadores de adensamento, compactação, encrostamento, susceptibilidade à perda de solo e de produtividade e degradação ambiental (Laurindo et al., 2009).

Operações agrícolas, como queimadas, causam perda de nutrientes (Knicker et al., 2005), deterioração das propriedades químicas do solo (Dick et al., 2008), reduzindo seu potencial produtivo (Heringer, 2000). Já a utilização de maquinário e revolvimento do solo, provocam a quebra dos agregados e, consequentemente, redução dos poros (Pacheco; Cantalice, 2011). 
Os Cambissolos são constituídos por material mineral com horizonte B incipiente (Bi), apresentam textura franco-arenosa ou mais argilosa dependendo da sua localização, possuem minerais primários e altos teores de silte até mesmo nos horizontes superficiais, podendo sofrer com processos erosivos (EMBRAPA, 2006). Cambissolos que apresentam espessura no mínimo mediana, entre $50-100 \mathrm{~cm}$ de profundidade, e sem restrição de drenagem, em relevo pouco movimentado, apresentam bom potencial agrícola. Já os Cambissolos Háplicos Tb Distróficos apresentam argila de atividade baixa e baixa saturação por bases ( $\mathrm{V}<50 \%)$ na maior parte dos primeiros $100 \mathrm{~cm}$ do horizonte B (EMBRAPA, 2006).

O monitoramento da qualidade do solo, isto é, da capacidade do solo para desempenhar funções relacionadas à sustentação da diversidade biológica, à manutenção da qualidade do ambiente, à promoção da saúde de plantas e animais e à sustentação de estruturas socioeconômicas e de habitação humana (Doran; Parkin, 1994), é fundamental para que haja a adoção de práticas de manejo que ajudem não só na conservação das propriedades físicas e químicas, mas também na organização territorial, favorecendo o planejamento ambiental e o uso sustentável do solo.

Nesse sentido, a utilização de indicadores de qualidade do solo, como análise da textura, porosidade, densidade do solo e estabilidade de agregados em água, é considerada essencial para o monitoramento de impactos de fenômenos naturais ou de ações antrópicas (Arshad; Martin, 2002), pensando na sustentabilidade ambiental, agrícola e econômica.

Nesse contexto, a presente pesquisa se desenvolve na bacia hidrográfica do Córrego dos Micos, localizada na Área de Proteção Ambiental de Cairuçu, no município de Paraty, no litoral sul do Estado do Rio de Janeiro; e tem como objetivo analisar a qualidade de um Cambissolo Háplico sob diferentes usos (floresta, pasto e aipim) a partir do impacto da erosão hídrica visando a conservação dos mesmos.

\section{Materiais e Métodos}

Área de estudo

A bacia hidrográfica do Córrego dos Micos (BHCM) possui aproximadamente 723 hectares e está localizada na parte central da Área de Proteção Ambiental do Cairuçu (APA-Cairuçu) (Figura 1). As principais atividades desenvolvidas na bacia são: agricultura familiar com o cultivo de aipim, abacaxi, feijão e banana; e a pecuária extensiva. 


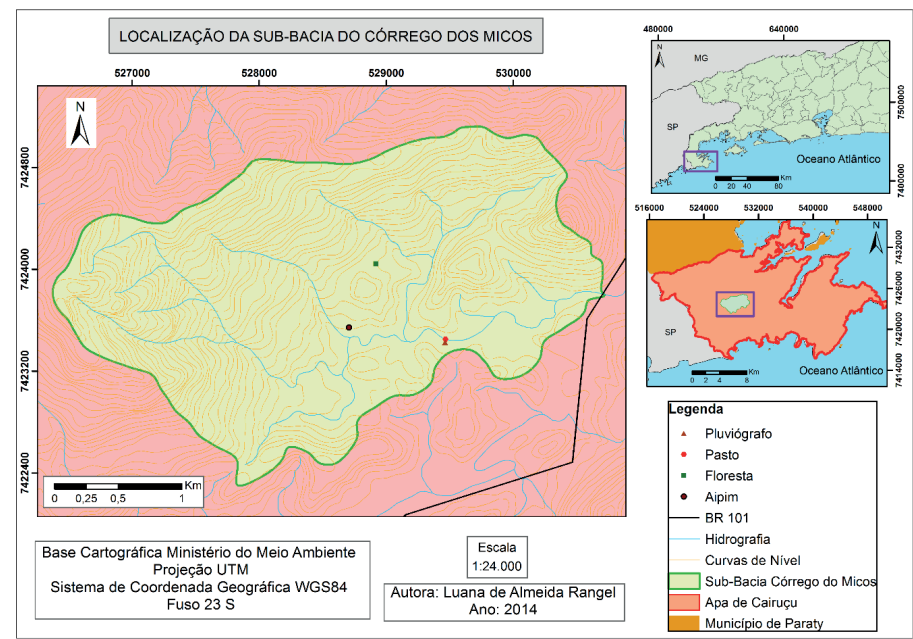

Figura 1 - Localização da APA Cairuçu e da bacia do Córrego dos Micos.

Fonte: Elaboração própria, 2014.

Essa bacia foi escolhida por apresentar fragmentos florestais de tamanhos expressivos, que estão sendo ameaçados pela expansão de áreas para cultivo e práticas constantes de queimadas. Já que esses fragmentos florestais pertencem ao Bioma Mata Atlântica, podem ser considerados estratégicos para a conservação da biodiversidade, constituindo um corredor ecológico entre a Reserva Ecológica da Juatinga, o Parque Estadual da Serra do Mar e o Parque Nacional da Serra da Bocaina (Gomes et al., 2004).

Além disso, a APA Cairuçu está inserida em uma área considerada prioritária para conservação, segundo o Ministério do Meio Ambiente (Brasil, 2004), a área da Serra da Bocaina, onde é destacada a importância do Bioma Mata Atlântica e sua prioridade de conservação é definida como extremamente alta.

A área montante da BHCM possui encostas íngremes com altitude de aproximadamente 800 metros, portanto, os remanescentes florestais de Mata Atlântica se encontram em estágio avançado de sucessão. Já a área à jusante da bacia, próxima a BR-101, sofre com a ocupação humana e com os impactos das atividades agropecuárias. 
O arcabouço geológico da região da APA do Cairuçu é formado predominantemente por granitos e gnaisses do Complexo GnáissicoGranitóide de idade proterozóica (Guerra et al., 2013). Já o tipo de solo predominante é o Cambissolo Háplico Tb Distrófico, ocupando quase toda a área da bacia (Rangel, 2014).

A classificação climática regional desta área corresponde ao clima tropical úmido, com sazonalidade no regime das precipitações (estação chuvosa x seca), sendo que no município de Paraty, a pluviosidade anual varia entre 768 a $2.045 \mathrm{~mm}$ (ICMBIO, 2004).

\section{Coletas e Análises Laboratoriais}

Para a realização da pesquisa, foram coletadas amostras de solo em três áreas com diferentes usos: floresta, aipim e pasto (Figura 2). As amostras foram coletadas em três repetições nas profundidades de 0-10 cm e 10-20 cm, no mês de setembro de 2013.
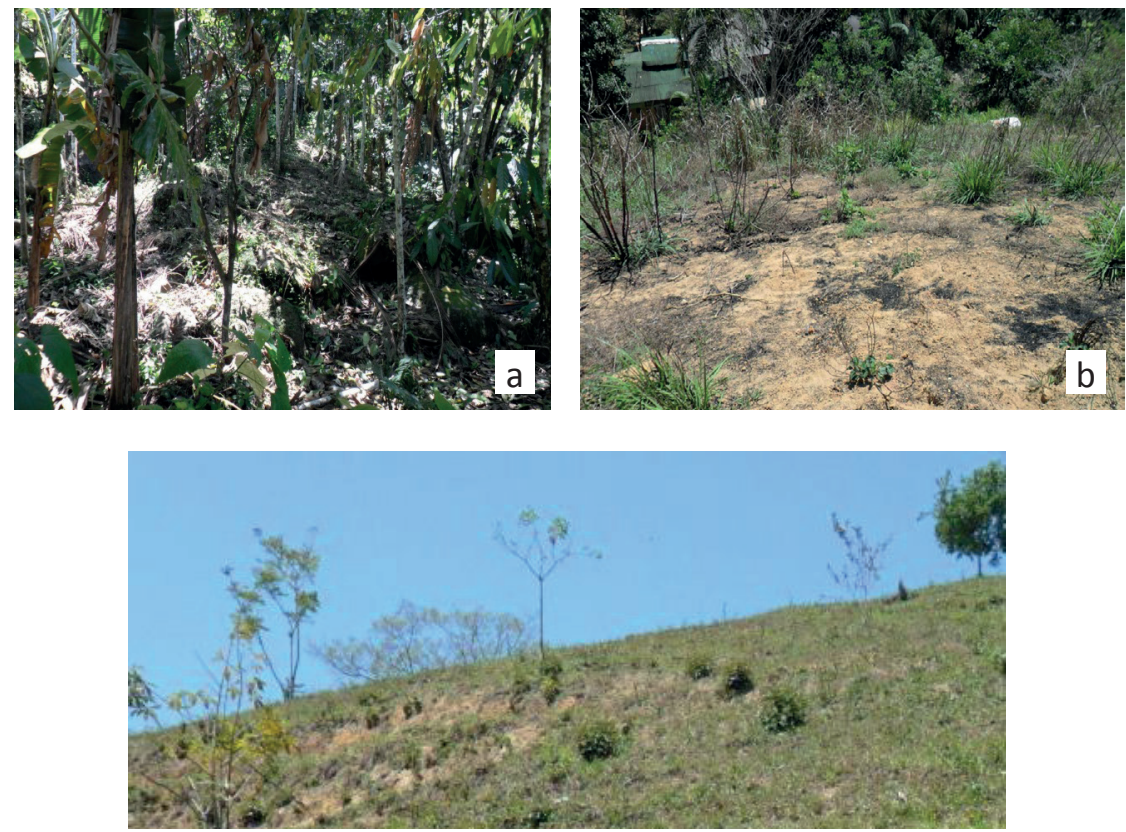

Figura 2 - Diferentes usos da terra estudados na BHCM. (a) área de floresta, (b) área de cultivo de aipim com queimada recente, (c) área de pastagem com início de processo erosivo. 
Para a análise da textura do solo foi utilizado o método da Embrapa (2011) de análise granulométrica a partir da dispersão total de partículas do solo utilizando a pipeta. A partir dos resultados obtidos, as amostras foram classificadas de acordo com o triângulo textural elaborado pela Sociedade Brasileira de Ciência do Solo (IBGE, 2015).

Para a determinação da densidade aparente do solo, é utilizado o método do anel volumétrico, proposto pela Embrapa (2011). Já para determinar a estabilidade de agregados em água, obedeceu-se o método proposto por Yoder (1936) e modificado por Castro Filho et al. (1998; 2002).

Após pesados, os valores obtidos nos peneiramentos são usados para cálculo do Diâmetro Médio Ponderado (DMP), que é tanto maior quanto maior for a percentagem de agregados grandes retidos nas peneiras com malhas maiores; do Diâmetro Médio Geométrico (DMG), que é uma estimativa do tamanho médio dos agregados que mais ocorrem no solo; e do Índice de Estabilidade dos Agregados (IEA), que é uma medida da agregação total, sem considerar as classes de distribuição de tamanho dos agregados, que pode refletir na resistência do solo à erosão (Castro Filho et al., 1998; 2002). As equações utilizadas foram modificadas por Castro Filho et al. (1998) de Kemper e Rosenau (1986).

\section{Dados de chuva}

Para coleta dos dados pluviométricos, foi instalado, em janeiro de 2013, um pluviógrafo da marca Irriplus, que registrou, de hora em hora, os índices pluviométricos. A instalação ocorreu antes da realização das coletas para poder avaliar os totais pluviométricos mensais antecedentes e a influência da chuva no processo de erosão. O pluviógrafo foi instalado próximo à área de pastagem.

\section{Resultados e Discussão}

A partir dos resultados de estabilidade de agregados em água, é possível analisar não só o impacto do pisoteio, mas também, a influência da água da chuva que reage de formas diferentes à superfície com e sem vegetação. Portanto, a erosividade da chuva e a erodibilidade do solo são fatores que respondem de diferentes formas dependendo do uso e do tipo de manejo do solo. 
Considerando os totais mensais de chuva, a partir da leitura diária do pluviógrafo instalado, janeiro e fevereiro apresentaram maiores amplitudes para o ano de 2013 (315,6 e 275,4 mm, respectivamente). Estes meses representam $37,6 \%$ do total de chuva anual, caracterizando períodos mais úmidos (Figura 4). Em contrapartida, os meses mais secos são agosto e setembro (34,5 e 51,1 mm, respectivamente), que representam $5,4 \%$ do total mensal das chuvas anuais.

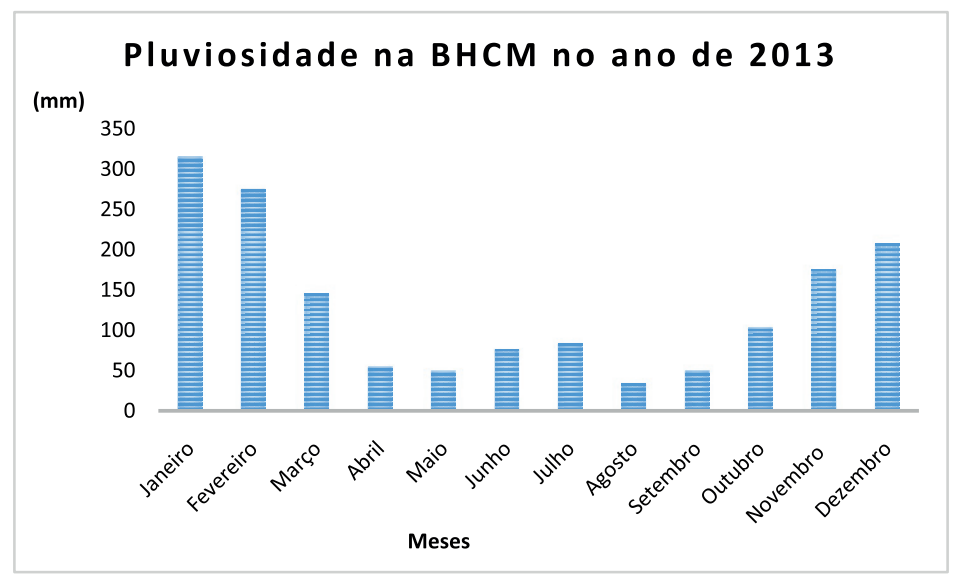

Figura 4 - Gráfico de pluviosidade mensal da BHCM, no ano de 2013

Fonte: Elaboração própria (2014).

Com relação aos processos erosivos, fica evidente a predominância de erosão laminar com evolução para ravinas na área de pastagem e na de cultivo de aipim.

Analisando a estabilidade de agregados (Tabela 1), verifica-se que os valores do Diâmetro Médio Ponderado (DMP) e, consequentemente, do Diâmetro Médio Geométrico (DMG), foram maiores na área de floresta nas duas profundidades. Através do teste estatístico de Tukey é possível inferir que o cultivo do aipim, nas duas profundidades, e o pasto, na profundidade de 10-20 cm, apresentaram diferença significativa em relação ao floresta. 
Tabela 1 - Resultado da análise de estabilidade de agregados em água nos três usos

\begin{tabular}{|c|c|c|c|c|c|c|}
\hline \multicolumn{7}{|c|}{ ÍNDICES DE AGREGAÇÃO DO SOLO NAS DIFERENTES ÁREAS } \\
\hline & \multicolumn{3}{|c|}{ Profundidade de $0-10 \mathrm{~cm}$} & \multicolumn{3}{|c|}{ Profundidade de $10-20 \mathrm{~cm}$} \\
\hline & Floresta & Pasto & Aipim & Floresta & Pasto & Aipim \\
\hline $\mathrm{DMP}(\mathrm{mm})$ & $2,71 \mathrm{~A}$ & $2,48 \mathrm{AB}$ & $1,99 \mathrm{~B}$ & $2,08 \mathrm{~A}$ & $1,64 \mathrm{AB}$ & $1,75 B$ \\
\hline $\mathrm{DMG}(\mathrm{mm})$ & $2,4 \mathrm{~A}$ & $1,98 \mathrm{~A}$ & $1,3 \mathrm{~B}$ & $1,74 \mathrm{~A}$ & $1,11 \mathrm{~B}$ & $1,08 B$ \\
\hline IEA (\%) & $96,89 \mathrm{~A}$ & $93,07 \mathrm{~A}$ & $88,4 \mathrm{AB}$ & $92,68 \mathrm{~A}$ & $89,04 A B$ & $87,77 \mathrm{~B}$ \\
\hline Macroagregados (\%) & $95,37 \mathrm{~A}$ & $91,2 \mathrm{~A}$ & 81,69 B & $86,45 \mathrm{~A}$ & $79,03 \mathrm{AB}$ & $75,5 B$ \\
\hline Microagregados (\%) & $4,63 \mathrm{~A}$ & $8,8 \mathrm{~A}$ & $18,31 \mathrm{~B}$ & $13,55 \mathrm{~A}$ & $20,97 A B$ & $24,5 B$ \\
\hline Agregados $>2 \mathrm{~mm}(\%)$ & $86,22 \mathrm{~A}$ & $74,99 \mathrm{~A}$ & $54,26 \mathrm{~B}$ & $55,07 \mathrm{~A}$ & $34,65 \mathrm{AB}$ & $43,22 \mathrm{~B}$ \\
\hline
\end{tabular}

Linhas seguidas da mesma letra, na mesma profundidade, não

diferem significativamente pelo teste Tukey $(p>0,05)$.

Fonte: Elaboração própria (2014).

Como era esperado, a área de floresta teve os maiores índices de agregação, enquanto o aipim apresentou os menores índices de estabilidade na profundidade de $0-10 \mathrm{~cm}$, e o pasto apresentou os menores índices na profundidade de $10-20 \mathrm{~cm}$. Isto está diretamente relacionado com o não revolvimento do solo, a proteção do solo pela copa das árvores e pela serapilheira que impedem o contato direto da gota de chuva, o acúmulo de matéria orgânica devido ao aporte de serapilheira na área de floresta, evidenciando assim, que a matéria orgânica do solo, viva ou morta, exerce um papel fundamental na agregação do solo como diversos autores já destacaram (Castro Filho et al., 2002; Denef et al., 2001; Elmholt et al., 2008), principalmente nos primeiros centímetros do solo.

Observa-se que o pasto apresentou baixos valores para o DMP $(1,64$ $\mathrm{mm})$ e o DMG $(1,11 \mathrm{~mm})$ na profundidade de $10-20 \mathrm{~cm}$, isto pode estar ocorrendo devido ao intenso pisoteio que provoca a quebra da estrutura do agregado, principalmente nos primeiros centímetros do solo. O valor de DMG é considerado baixo, o que reitera a afirmação de Castro Filho et al. (1998), que quanto menor for o DMG, menos espaços porosos existirão entre os agregados, diminuindo, portanto, a infiltração e aumentando a erosão. 
Um agravante na área de cultivo de aipim são as queimadas para "limpar" o solo. Este processo, a longo prazo, diminui as propriedades químicas e físicas do solo, e pode gerar incêndios maiores, atingindo fragmentos de Mata Atlântica à montante da bacia, caso não seja controlado adequadamente. Cassol et al. (2004) destacam que como consequências da queima podem ocorrer modificações na taxa de infiltração e evapotranspiração da água do solo, na porosidade e no aumento do grau de suscetibilidade dos solos à erosão hídrica e eólica.

Canellas et al. (2003), ao estudarem um Cambissolo Háplico sob cultivo de cana-de-açúcar com diferentes formas de manejo, destacaram que a queima influenciou negativamente na presença de determinados nutrientes como potássio e cálcio, bem como na redução da capacidade de troca catiônica (CTC).

Matos et al. (2008) destacam que agregados estáveis em água contribuem para um solo mais poroso e, consequentemente, favorecem a infiltração e a resistência à erosão. Já os agregados não estáveis, quando presentes na superfície, tendem a desaparecer e dispersar-se sob o impacto das gotas de chuva.

É importante destacar a porcentagem de microagregados no pasto e no aipim na profundidade de $10-20 \mathrm{~cm}, 20,97 \%$ e $24,5 \%$, respectivamente. Esses valores elevados estão diretamente relacionados à menor cobertura vegetal nestes usos que proporcionam maior impacto da gota de chuva no solo. Fattet et al. (2011) destacam que durante os eventos de precipitação intensa, o impacto inicial e o encharcamento do solo quebram os macroagregados produzindo microagregados $(<0,25 \mathrm{~mm})$. Esse processo, segundo Legout et al. (2005), favorece o desenvolvimento de crostas no topo do solo, escoamento superficial e erosão entre ravinas.

Em contrapartida, Ghestem et al. (2011) afirmam que apesar dos macroagregados serem mais estáveis e diminuírem o risco de erosão, podem facilitar a infiltração de água no solo, aumentando o risco de movimentos de massa em encostas íngremes em eventos extremos de chuva.

A área de pastagem teve seus valores de IEA maiores do que a área de cultivo de aipim nas duas profundidades (93,07\% e 89,04\% na pastagem e 88,4\% e 87,77\% no aipim), isto está relacionado à dinâmica radicular do pasto nos horizontes superficiais, uma vez que, segundo Tisdall e Oades (1982), as raízes e as hifas são as maiores responsáveis pela estabilidade dos macroagregados. 
Diversos autores (Zolfaghari; Hajabbasi, 2008; An et al., 2010; Fattet et al., 2011) destacam a diferença entre os índices de agregação de áreas de floresta, cultivo e pastagem, onde a área de floresta apresenta maior IEA devido ao aporte de matéria orgânica que favorece a cimentação do solo (Hillel, 2003).

Bronick e Lal (2005) afirmam que além de aspectos como manejo e clima, a agregação também está associada à textura do solo, sendo assim, o baixo teor de argila pode estar influenciando na não formação de agregados maiores. Diante disso, observa-se que a área de floresta apresentou os maiores teores de argila nas duas profundidades (37,5\% e $39,5 \%$ ), o que corrobora os valores elevados de agregação do solo (Tabela 2).

Sabendo que solos com elevada presença de silte e areia fina são mais suscetíveis a processos erosivos (Guerra; Mendonça, 2004; Morgan, 2005), é possível afirmar que a área de cultivo de aipim está mais propensa a esse tipo de processo, pois apresentou maiores teores de silte nas duas profundidades (36,58\% e 29,01\%), e de areia fina (22,53\% e $31,32 \%)$.

Já a área de pasto apresentou os maiores teores de areia, 61, 34\% na profundidade de 0-10 $\mathrm{cm} \mathrm{e} \mathrm{47,} \mathrm{06 \%} \mathrm{na} \mathrm{profundidade} \mathrm{de} \mathrm{10-20} \mathrm{cm.} \mathrm{Elevados}$ teores de areia podem impactar negativamente na formação de agregados do solo, o que prejudica a estruturação do mesmo.

Sabe-se que a porosidade possui uma relação inversa com a densidade do solo e que a textura e estrutura do solo explicam, em grande parte, o tipo, tamanho, quantidade e continuidade dos poros. A floresta apresentou os maiores valores de porosidade $\left(0,66 \mathrm{~m}^{3} \mathrm{~m}^{-3} \mathrm{e} 0,62 \mathrm{~m}^{3} \mathrm{~m}^{-3}\right)$ nas profundidades de 0-10 cm e 10-20 cm. Isso já era esperado, visto que a área também apresentou os menores valores de densidade do solo.

Kiehl (1979) destaca que a densidade aparente tende a aumentar com a profundidade, já que a compactação é maior, o teor de matéria orgânica é reduzido e a agregação tende a ser menor. Todos esses fatores foram observados para os três usos analisados. $\mathrm{O}$ autor ainda destaca que valores de densidade aparente entre 1,1 e 1,6 g/ $\mathrm{cm}^{3}$ representam predominância de frações minerais e manejo inadequado do solo. Portanto, os solos analisados se encaixam na proposição de Kiehl (1979).

Na Tabela 2 é possível observar que o pasto apresentou os maiores valores de densidade $\left(1,53 \mathrm{~g} / \mathrm{cm}^{3}\right.$ e $\left.1,55 \mathrm{~g} / \mathrm{cm}^{3}\right)$, devido ao pisoteio do gado que compacta o solo, e consequentemente, os menores valores de porosidade $\left(0,6 \mathrm{~m}^{3} \mathrm{~m}^{-3}\right.$ e $\left.0,59 \mathrm{~m}^{3} \mathrm{~m}^{-3}\right)$. 
Tabela 2 - Resultado da análise das propriedades físicas do solo nos três usos

\begin{tabular}{cccccccccc}
\hline Uso & Profundidade & $\begin{array}{c}\text { Areia } \\
\text { Fina }\end{array}$ & $\begin{array}{c}\text { Areia } \\
\text { Grossa }\end{array}$ & $\begin{array}{c}\text { Areia } \\
\text { Total }\end{array}$ & Silte & Argila & $\begin{array}{c}\text { Densidade } \\
\text { Aparente }\end{array}$ & $\begin{array}{c}\text { Porosidade } \\
\left(\mathrm{m}^{3} \mathrm{~m}^{-3}\right)\end{array}$ & $\begin{array}{c}\text { Classe } \\
\text { Textural }\end{array}$ \\
\hline Pasto & $0-10 \mathrm{CM}$ & 7,56 & 53,78 & 61,34 & 17,16 & 21,50 & 1,53 & 0,60 & $\begin{array}{c}\text { Franco Argilo } \\
\text { Arenoso }\end{array}$ \\
\cline { 2 - 9 } & $10-20 \mathrm{CM}$ & 9,05 & 38,02 & 47,06 & 20,94 & 32,00 & 1,55 & 0,59 & $\begin{array}{c}\text { Franco Argilo } \\
\text { Arenoso }\end{array}$ \\
\hline \multirow{2}{*}{ Aipim } & $0-10 \mathrm{CM}$ & 22,53 & 10,90 & 33,43 & 36,57 & 30,00 & 1,44 & 0,62 & $\begin{array}{c}\text { Franco } \\
\text { Argiloso }\end{array}$ \\
\cline { 2 - 9 } & $10-20 \mathrm{CM}$ & 31,32 & 12,17 & 43,49 & 29,01 & 27,50 & 1,47 & 0,60 & $\begin{array}{c}\text { Franco } \\
\text { Argiloso }\end{array}$ \\
\hline \multirow{2}{*}{ Floresta } & $0-10 \mathrm{CM}$ & 11,19 & 30,53 & 40,78 & 20,78 & 37,50 & 1,34 & 0,66 & $\begin{array}{c}\text { Franco } \\
\text { Argiloso }\end{array}$ \\
\cline { 2 - 9 } & $10-20 \mathrm{CM}$ & 11,13 & 30,10 & 41,23 & 19,28 & 39,50 & 1,37 & 0,62 & $\begin{array}{c}\text { Franco } \\
\text { Argiloso }\end{array}$ \\
\hline
\end{tabular}

Observação: Os valores de areia, argila e silte estão expressos em porcentagem (\%); os valores de densidade do solo estão expressos em g/ $\mathrm{cm}^{3}$; os valores de porosidade estão expressos em $\mathrm{m}^{3} \mathrm{~m}^{-3}$.

Fonte: Elaboração própria (2014).

Apesar dos valores diferentes, não houve diferença significativa entre a densidade e a porosidade do solo para os diferentes usos. Isto pode estar diretamente relacionado com o fato de que tanto a área de pastagem como a de cultivo de aipim, são propriedades familiares e, portanto, não são utilizadas de forma intensa, o que reflete no uso e no manejo do solo.

\section{Considerações Finais}

Os indicadores de qualidade física dos solos foram considerados satisfatórios por permitirem constatar instabilidade da estrutura em alguns usos. Através da comparação entre os diferentes usos, verificou-se que está havendo degradação da estrutura do solo no plantio de aipim. Isso foi verificado a partir dos índices de agregação do solo, que refletem maior concentração de microagregados, bem como menores DMP e DMG.

Logo, para que seja favorecida a formação de agregados mais estáveis, é necessária a cooperação entre processos físicos e biológicos, tais como o crescimento da raiz e aumento da atividade microbiana. Nesse sentido, uma alternativa para aumentar a estabilidade dos agregados seria a utilização de 
formas de manejo que favoreçam a incorporação de matéria orgânica no solo ou a realização de rotação de usos, bem como a redução das práticas de queimadas realizadas para "limpar" o solo após a colheita.

Conclui-se que é de suma importância evitar a estagnação dos solos cultiváveis na bacia do Córrego dos Micos, a fim de evitar a expansão da atividade agrícola, e consequentemente, o desmatamento de fragmentos de Mata Atlântica remanescentes. Isso só será possível se a qualidade do solo for preservada através de práticas de manejo adequadas.

Nota

Agradecimentos ao Conselho Nacional de Desenvolvimento Científico e Tecnológico (CNPq) e à Fundação de Amparo à Pesquisa do Estado do Rio de Janeiro (FAPERJ) pelo financiamento da pesquisa no período de 2012 até 2015; e à Coordenação de Aperfeiçoamento de Pessoal de Nível Superior (CAPES) pelo financiamento da bolsa de doutorado de 2014 até o presente momento.

\section{Referências}

AN, S. et al. Soil aggregation, aggregate stability, organic carbon and nitrogen in different soil aggregate fractions under forest and shrub vegetation on the Loess Plateau, China. Catena, v. 81, p. 226-233, 2010.

ARSHAD, M. A.; MARTIN, S. Identifying critical limits for soil quality indicators in agro-ecosystems. Agriculture, Ecosystems and Environment, Amsterdan, v. 88, p. 153-160, 2002.

BRASIL. Ministério do Meio Ambiente. Portaria n 126, de 27 de maio de 2004. Criação do mapa de Áreas Prioritárias para a Conservação, Utilização Sustentável e Repartição de Benefícios da Biodiversidade Brasileira. 2004. Disponível em: <http://www.mma.gov.br/biodiversidade/projetos-sobre-a-biodiveridade/ projeto-de-conserva\%C3\%A7\%C3\%A3o-e-utiliza\%C3\%A7\%C3\%A3osustent\%C3\%A1vel-da-diversidade-biol\%C3\%B3gica-brasileira-probioi/\%C3\%A1reas-priorit\%C3\%A1rias>. Acesso em: 27 ago. 2012.

BRONICK, C. J.; LAL, R. Soil structure and management: A review. Geoderma, v. 124, p. 3-22, 2005.

CANELLAS, L. P. et al. Propriedades químicas de um Cambissolo cultivado com cana-de-açúcar, com preservação do palhiço e adição de vinhaça por longo tempo. Revista Brasileira de Ciência do Solo, v. 27, p. 935-944, 2003.

CASSOL, E. A. et al. Erosividade das chuvas em Taquari, RS, determinada pelo índice EI30, no período de 1963 a 1999. In: Reunião Brasileira de Manejo e 
Conservação de Solo e Água, 15. 2004, Santa Maria. Anais... Santa Maria: SBCS, 2004.

CASTRO FILHO, C. et al. Estabilidade dos agregados e sua relação com o teor de carbono orgânico num Latossolo Roxo Distrófico, em função de sistemas de plantio, rotações de culturas e métodos de preparo das amostras. Revista Brasileira de Ciência do Solo, v. 22, p. 527-538, 1998.

CASTRO FILHO, C. et al. Aggregate stability under different soil management systems in a redlatosol in the state of Parana, Brazil. Soil and Tillage Research, v. 65, n. 1, p. 45-51, 2002.

DENEF, K. et al. Importance of macroaggregate dynamics in controlling soil carbon stabilization: short-term effects of physical disturbance induced by drywet cycles. Soil Biology and Biochemistry, v. 33, p. 2145-2153, 2001.

DICK, D. P. et al. Impacto da queima nos atributos químicos do solo, na composição da matéria orgânica e na vegetação. Pesquisa Agropecuária Brasileira, v. 43, p. 633-640, 2008.

DORAN, J. W.; PARKIN, T. B. Defining and assessing soil quality. In: DORAN, J. W. et al. (Ed). Defining soil quality for a sustainable environment. Soil Science Society of America Journal, Madison, Special Publication, n. 35, p. 3-22, 1994.

ELMHOLT, S. et al. Soil management effects on aggregate stability and biological binding. Geoderma, v. 144, n. 3-4, p. 455-467, 2008.

EMBRAPA. Centro Nacional de Pesquisa de Solos (Rio de Janeiro, RJ). Sistema brasileiro de classificação de solos. Rio de Janeiro: EMBRAPA-SPI, 2006.

EMBRAPA. Centro Nacional de Pesquisa de Solos (Rio de Janeiro, RJ). Manual de métodos de análise de solo. Rio de Janeiro: EMBRAPA-CNPS, 2011. 212p.

FATTET, M. et al. Effects of vegetation type on soil resistance to erosion: Relationship between aggregate stability and shear strength. Catena, v. 87, p. 60-69, 2011.

GHESTEM, M. et al. The influence of plant root systems on subsurface flow: implications for slope stability. BioScience, v. 61, p. 869-879, 2011.

GOMES, L. J. et al. Dinâmica Espacial do uso da terra na Zona de Amortecimento do Parque Nacional da Serra da Bocaina. In: Anais - II Simpósio Regional de Geoprocessamento e Sensoriamento Remoto. Aracaju/SE, 10 a 12 de novembro de 2004.

GUERRA, A. J. T; MENDONÇA, J. K. S. Erosão dos Solos e a Questão Ambiental. In: VITTE, A. C.; GUERRA, A. J. T. (Org.). Reflexões sobre a Geografia Física no Brasil. Rio de Janeiro: Bertrand Brasil, 2004.

GUERRA, A. J. T. et al. The geomorphology of Angra dos Reis and Paraty Municipalities, Southern Rio de Janeiro State. Revista Geonorte, v. 8, n. 1, p. 1-21, 2013.

HERINGER, I. Efeitos do fogo por longo período e de alternativas de manejo sobre o solo e a vegetação de uma pastagem natural. 2000. 208f. Tese (Doutorado em Zootecnia/ Plantas Forrageiras) - Universidade Federal do Rio Grande do Sul, Porto Alegre, 2000. 
HILLEL, D. Introduction to Environmental Soil Physics. Burlington: Academic Press, 2003. 73-89p.

ICMBIO. Plano de Manejo da APA de Cairuçu. 2004. Disponível em: < http:// www.icmbio.gov.br/portal/biodiversidade/unidades-de-conservacao/biomasbrasileiros/marinho/unidades-de-conservacao-marinho/2240-apa-de-cairucu. html>. Acesso em: 06 ago. 2012.

IBGE. Manual técnico de pedologia: guia prático de campo. Rio de Janeiro: IBGE - Coordenação de Recursos Naturais e Estudos Ambientais, 2015. 134p.

KELTING, D. L. et al. Soil quality assessment in domesticated forests - a southern pine example. Forest Ecology and Management, v. 122, p. 167-185, 1999.

KEMPER, W. D.; ROSENAU, R. C. Aggregate stability and size distribution. In: KLUTE, A. (Ed.). Methods of soil analysis - Part I: Physical and minerological methods. Wisconsin: Madison, 1986. p. 425-442.

KIEHL, E. J. Manual de edafologia, relações solo-planta. São Paulo: Ceres, 1979.

KNICKER, H. et al. Wildfire induced alterations of the chemical composition of humic material in a Dystric Xerochrept under a Mediterranean pine forest (Pinuspinaster Aiton). Soil Biology and Biochemistry, Oxford, v. 37, n. 4, p. 701718, 2005.

LAURINDO, M. C. O. et al. Atributos físicos do solo e teor de carbono orgânico em sistemas de plantio direto e cultivo mínimo. Revista Engenharia na agricultura, v. 17, n. 5, p. 367-374, 2009.

LEGOUT, C. et al. Aggregate breakdown dynamics under rainfall compared with aggregate stability measurement. European Journal of Soil Science, v. 56, p. 225-237, 2005.

MATOS, E. S. et al. Estabilidade de agregados e distribuição de carbono e nutrientes em Argissolo sob adubação orgânica e mineral. Pesquisa Agropecuária Brasileira, v. 43, p. 1221-1230, 2008.

MORGAN, R. P. C. Soil Erosion and Conservation. England: Blackwell, 2005.

PACHECO, E. P.; CANTALICE, J. R. B. Análise de trilha no estudo dos efeitos de atributos físicos e matéria orgânica sobre a compressibilidade e resistência à penetração de um Argissolo cultivado com cana-de-açúcar. Revista Brasileira Ciência do Solo, v. 35, p. 417-428, 2011.

PEDROTTI, A.; MELLO JÚNIOR, A. V. Avanços em ciência do solo: a física do solo na produção agrícola e qualidade ambiental. São Cristovão: EdUFS, 2009.

PORTELA, J. et al. Restauração da estrutura do solo por sequências Culturais implantadas em semeadura direta, e sua Relação com a erosão hídrica em distintas Condições físicas de superfície. Revista Brasileira de Ciência do Solo, Viçosa, MG, v. 34, n. 1, p.1353-1364, 2010.

RANGEL, L. A. O Impacto da Utilização de Trilhas na Área de Proteção Ambiental de Cairuçu - Paraty - Rio de Janeiro. 2014. 184 f. Dissertação (Mestrado em Geografia) - Programa de Pós-Graduação em Geografia, Universidade Federal do Rio de Janeiro. Rio de Janeiro, 2014. 
SILVA, A. A.; CASTRO, S. S. Indicadores macro e micromorfológicos da qualidade física de um Latossolo vermelho textura média cultivado com canade-açúcar na microrregião de Quirinópolis, Goiás. Boletim Goiano de Geografia (Online), Goiânia, v. 34, n. 2, p. 233-251, 2014.

SCHNEIDER, P. et al. Morfologia do solo: subsídio para caracterização e interpretação de solos a campo. Guaíba: Agrolivros, 2007.

TISDALL, J. M.; OADES, J. M. Organic matter and water stable aggregates in soils. Soil Science American Journal, v. 33, p. 141-163, 1982.

YODER, R. E. A direct method of aggregate analysis of soils and a study of the physical nature of erosion losses. Journal American Society Agronomy, v. 28, p. 337-351, 1936.

ZOLFAGHARI, A. A.; HAJABBASI, M. A. Effect of different land use treatment on soil structural quality and relation with fractal dimensions. International Journal Soil Science, v. 3, n. 2, p. 101-108, 2008.

Luana de Almeida Rangel: Possui graduação em Geografia pela Universidade Federal do Rio de Janeiro. Especialização em Análise Ambiental e Gestão do Território pela Escola Nacional de Ciências Estatísticas (ENCE/IBGE). Mestrado em Geografia, com ênfase em Planejamento Ambiental, pela Universidade Federal do Rio de Janeiro. Atualmente é aluna de Doutorado em Geografia da Universidade Federal do Rio de Janeiro e integrante do Laboratório de Geomorfologia Ambiental e Degradação dos Solos (LAGESOLOS-UFRJ).

Antonio José Teixeira Guerra: Possui graduação em Geografia pela Universidade Federal do Rio de Janeiro. Mestrado em Geografia pela Universidade Federal do Rio de Janeiro. Doutorado em Erosão dos Solos pela Universidade de Londres. Pós-Doutorado em Erosão dos Solos na Universidade de Oxford e na Universidade de Wolverhampton. Atualmente é professor Titular da Universidade Federal do Rio de Janeiro (UFRJ), pesquisador 1A do Conselho Nacional de Desenvolvimento Científico e Tecnológico (CNPq) e Coordenador do Laboratório de Geomorfologia Ambiental e Degradação dos Solos (LAGESOLOS-UFRJ).

Contribuição de cada autor no desenvolvimento do artigo

Todos os autores ofereceram substanciais contribuições científicas e intelectuais ao estudo. As tarefas de concepção e design do estudo, preparação, tabulação e análise dos dados e redação do manuscrito, bem como a revisão crítica, foram desenvolvidas em grupo. Ambos os autores foram responsáveis pelo desenvolvimento teórico-conceitual; pela aquisição de dados, interpretação e análise; e pelos procedimentos técnicos e tradução do artigo. 